\title{
Health Facilities in Kokrajhar District of Assam, India
}

\author{
Gwmsath Mushahary, Manjil Basumatary
}

\begin{abstract}
Health can be considered as the state of being free from illness or injury. A health facility is a facility where quality health care access is provided. The number and quality of health facilities in a country or region is common measures of that area's prosperity and quality of life. Therefore, health infrastructure is one of socio economic indicators of an area. As per the guideline of the WHO, the Doctor Population ratio should be 1:1000 but in case of India it is very pathetic as the ratio stands at 1:1456 (Economic survey 2019-20) and the state of Assam is more pathetic i.e 1:1800. A health status of a region is dependent on the health care availability provided in the region. The district Kokrajhar is situated in the westernmost part of Assam and is lacking far behind in health care facilities as compared to other districts of the state. Most of the families belong to the Below Poverty Line (BPL) category and their PCI is also one of the lowest. The reason for poor health care facilities in the district is mainly because of Doctors unwillingness to join the government services and their reluctance to serve in the rural areas. The main objective of this paper is to highlight the health facilities and health status of the district in comparison to the state and the country. The study is based on the secondary data sources and both descriptive and analytic methods have been used for the study. Statistical techniques are also used to represent the data. The study reveals that the causes of low status of health facilities in the region is due to lack of accessibility, poverty, insufficient medical equipment and insufficient workforce and cultural norms and due to all this, people of the district is facing many problems. The diseases like Typhoid, Jaundice, Eye problem, Malaria, Tuberculosis, Pneumonia etc are commonly seen in the district. . This study will aid the governments, NGOs, planners, administrators and above all the society as the research work highlights some of the hidden truths pertaining to health care facilities in the district.
\end{abstract}

Keywords: Health facility, Accessibility, Workforce, Poverty, Diseases.

\section{INTRODUCTION}

$\mathrm{H}$ ealth is considered as highly valued asset for all living beings. Health of the people is the foundation upon which the happiness and behavior of the people depend. In general, health encompasses the physical, mental, emotional, and social well-being. A good health condition of a person is linked with the availability of health facilities of that area. Infrastructure has been described as the basic support for the delivery of public health activities (Kumar and Gupta, 2012). The health conditions of the people of a nation largely depend on an effective and well developed health-care system

Revised Manuscript Received on June 13, 2020.

* Correspondence Author

Gwmsath Mushahary*, Guest Lecturer, Department of Geography, Gossaigaon College, Gossaigaon, Kokrajahr, Assam, India.

Dr. Manjil Basumatary, Teacher, Department of Geography, Gossaigaon College, Gossaigaon, Kokrajahr, Assam, India.

(c) The Authors. Published by Blue Eyes Intelligence Engineering and Sciences Publication (BEIESP). This is an open access article under the CC BY-NC-ND license (http://creativecommons.org/licenses/by-nc-nd/4.0/)
(Saikia and Das, 2014). The health facilities comprise of all the physical infrastructure and man power activists serving in the sector. The healthcare system faces some challenges that are, reduction in mortality rates, improved infrastructure, availability of health personnel, etc. A well-developed health infrastructure is dependent on the economic conditions of the country. The more developed countries have better health infrastructure and health care facilities and they have more potential to provide better health facilities to their citizens. The people of the advanced countries have high Per Capita Income (PCI) and because of that they can avail the opportunity for quality treatment. Health care of each and every individual is very vital for the overall economic development of a state or country (Paul et al, 2019). Health care facilities are provided by the National Health Mission, Ayushman Bharat, National Mental Health Programme etc. in the country by the Union Ministry of Health and Family Welfare. There are multiple systems set up in rural and urban areas of India including Primary Health Centres, Community Health Centers, Sub Centres and Government Hospitals to name a few. Indian heath care facilities in terms of quality and accessibility are one of the lowest in the world ranking at 145th position among 195 countries. Indian neighbours are in better position with China ranking at 48th, Srilanka at 71st, Bangladesh at 133rd and Bhutan at 134th. As per the World Health Organization (WHO) recommendation, the Doctor population ratio should be 1: 1000, which is 1: 1456 in India (Economic Survey, 2020) and Assam with 1:1800 (Sentinel, 2019). It clearly reflects the health facilities in the country as well as in the state of Assam. There are many reasons for such issues like Doctors are not interested to join the government services and many senior doctors who were serving in various medical colleges of the state had also taken voluntary retirement resulting in shortage of faculty in medical colleges. Doctors from other states are also not willing to come and serve in Assam. There are more than $50 \%$ posts in health services currently lying vacant. When advertisement is given to fill the vacant posts, the number of applicants is found to be lesser than the vacant posts (Choudhury, 2017). This is mainly due to lack of proper planning by the government.

The health care facilities in Kokrajhar district are very poor as compared to other districts of the state. The average health infrastructure ratio as per population of the district is also much lower than the national and state level. There are a number of factors which are responsible for such a low status of health infrastructure and other facilities in the district. The reasons are like lack of residential quarters for doctors and medical staff in the district as well as in the sub divisional level.

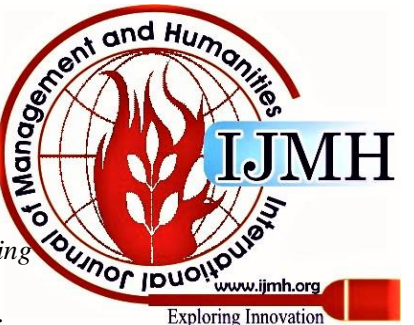


The state government has formulated a policy to attract the doctors to the rural areas like doctors willing to pursue their Post graduate course in the field must serve in the rural areas for a year. This policy has also failed to attract the doctors. Apart from this, the geographical location, political problems and socio economic conditions are also other reasons for the poor infrastructural facilities related to health sector in the district. Besides these, people in the district are to suffer from various health related issues mainly because of their poverty. The lack of accessibility, insufficient medical equipment and most importantly absence of manpower remained the major factors for the poor health facilities in the district in last few decades. There is a considerable shortage of hospitals, hospital beds and trained medical staffs such as doctors, nurses etc to mention a few. The rural-urban imbalance also hampers access to health care services. In rural areas, the accessibility is significantly lower as compared to urban areas. Children and women are under-represented in the health care workforce. About $90 \%$ people of the district are living in the rural areas. Their main occupation for livelihood is agriculture and other primary activities. The scope of economic development in the rural areas of the district is much lower than the urban areas. The poor management of the health infrastructure is frequently seen in the district.

The condition deteriorates as one move from urban to rural areas. About 80 percent of doctors, 75 percent of dispensaries and 60 percent of hospitals are found to be confined in urban areas only, whereas 72 percent of India's population lives in rural areas. Therefore, it is necessary to assess the current performance of healthcare system in various levels. There is 1, 56,231 Sub Centres functioning in the country, out of this 4621 are in the state of Assam with 161 in the Kokrjahar district. The total Public Health Centre (PHCs) in the country is 25,650 with 1014 and 45 in Assam and Kokrajhar district respectively. There are about 5624 Composite Health Care Centres (CHCs) in the country and out of this 4 are in Kokrajhar district. India has a total manpower of 8, 70,089 Accredited Social Health Activists (ASHA) workers in July 2013, followed by 2, 12,185 Auxiliary Nurse Midwife (ANMs), 27,421 doctors and 4078 Specialists. Besides, a number of health workers are serving in the nation but both human workforce and physical infrastructure are not sufficient to meet the requirement of the existing population. The district Kokrajhar is also not free from the shortfall of manpower and physical infrastructure. The access to health-care facilities in the rural areas across the northeastern states is limited by dysfunctional physical infrastructure, lack of equipment, lack of adequate health workers, lack of electricity and lack of proper road connectivity, etc.

\section{A. Statement of the Problem}

The health infrastructure is one of the most important indicators of our livelihood. The well-being of a country is dependent on the health care availability provided by the country. The health opportunities are not equally distributed in the world as more developed countries have more capacity to provide health facilities. In India too, the distribution of health care facility is not equally distributed. The North Eastern states of India in general and the state of Assam in particular remained deprived from opportunities of health facilities for a pretty long time. Of late, it is observed that the centre is taking keen interest in the promotion of health sector in the region. Out of total expenses on health, most of the expenses are paid out of pocket by patients and their relatives. In this write up an attempt has been made to identify the conditions of public health facilities prevailing in the Kokrajhar district and the causes of poor health facilities in the district. At present there are about 161 SCs, 45 PHCs, 4 CHCs and a Sub divisional Hospital and a District Hospital with limited manpower to manage it. This infrastructural facility is not adequate to serve its total population. The people of the district have been facing problem even for a simple maternal delivery case due to lack of quality medical treatment. People of the district are to travel outside the district to get better treatment as they cannot expect for quality treatment in the public health care centres in the district. There are problems like lack of workforce; insufficient medical equipment, lack of physical infrastructure, shortage of required medicines, etc. in the district. The biggest challenge of the district is that the majority of people live in rural areas and they are mostly from Below Poverty Line (BPL) families. Hence, they cannot afford to pay for their healthcare expenditure. etc.

\section{B. Objectives of the study: The following objectives are put forward for the stud}

1. To understand the health facilities in the state of Assam particularly in the district of Kokrajhar

2. To compare the health facilities at the national, state and district level.

3. To know the causes of poor health facilities in the district and finally

4. To suggest measures for the improvement of health facilities in the district of Kokrajhar.

\section{Review of Literature}

Health Infrastructure means the basic support for the delivery of public health activities. Health condition of a particular region depends on the availability of health infrastructure of that region. Good health gives the ability to a person to accomplish his tasks with more energy. Good health contributes to the production of consumable services because the better the state of health, the greater time available for income-generating or productive activities (Paul et al., 2019). The health condition of the people of a nation largely depends on an effective and well developed health-care system (Saikia and Das, 2014). Infrastructure has been described as the basic support for the delivery of public health activities (Kumar and Gupta, 2012). Further they have revealed that five components of health infrastructure can be broadly classified as: skilled workforce; integrated electronic information systems; public health organizations, resources and research. Health infrastructure is an important indicator for understanding the health care delivery provision and welfare mechanism in a country. A good health infrastructure depends on the economic conditions of the country.

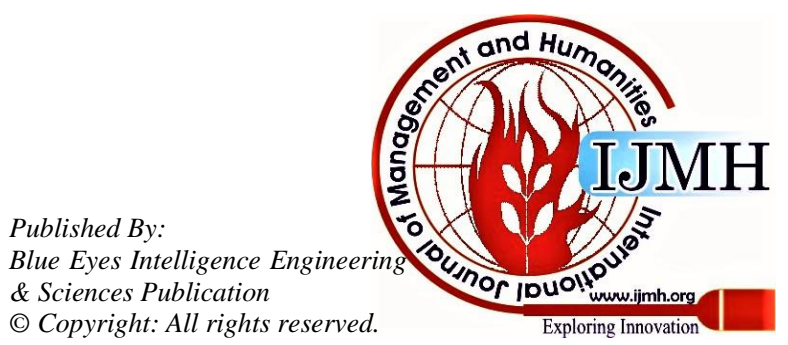


Ironically, India has one of the largest private health sectors in the world with over 80 per cent of ambulatory care being supported through out-of-pocket expenses (Duggal \& Gangolli, 2005). Further, it is said that a very large proportion of private providers are not qualified to provide modern health care because they are either trained in other systems of medicine such as traditional Indian systems like Ayurveda, Unani, Siddha, and homoeopathy or otherwise do not have any training. The lower-level health facilities are often not fully functional or reliable as the resources are quite thinly spread, and the population served by the most peripheral health facility vis-à-vis available staff is relatively high, (Bonu and Rani 2008), health leads to capability deprivation and hence poverty, which again stands for a low standard of living implying low intake of food, malnutrition, lack of basic amenities such as poor housing, clothing, safe drinking water and sanitation facilities (Buragohain, 2015).Improved sanitation, along with safe drinking water and adequate hygiene behavior are basic necessity for reduction of burden of water borne diseases and hence for good health of the individual and economy as a whole (Hajra, 2017).

\section{The Study Area}

Kokrajhar district is located in the western most part of
Assam and it lies in between 26 degree 18 minutes north to 26 degree 54 minutes north latitudes and 89 degree 46 minutes east to 90 degree 58 minutes east longitudes. The total area of the district is 3296.00 sq. $\mathrm{km}$, which accounts for 4.04 percent of the total geographical area of Assam. Kokrajhar is one of the 33th districts of Assam with 8.87 lakh population of which 4, 52,905 are males and 4, 34,237 are females. Out of the total population of the district, 8, 32, 201 people are living in rural areas and 54,941 are living in urban areas which reveals that more than $90 \%$ of the total people of the district are from rural areas. The district Kokrajhar is populated by various communities such as Bodos, Bengalis, Santals, Rajbongshis, Muslims, Assamese etc. The district Kokrajhar is the main gateway to the seven sister states of North East India. The district was originally a part of the undivided Goalpara district. In 1957, it was carved out as a civil sub division from the then Dhubri sub division of Goalpara district. In 1983, it was upgraded into a district. It is bounded in the north by Bhutan, in the east by the district of Chirang and Bongaigaon, in the south by the Dhubri district and in the west by the state of West Bengal.

Map of India showing Assam and Kokrajhar District

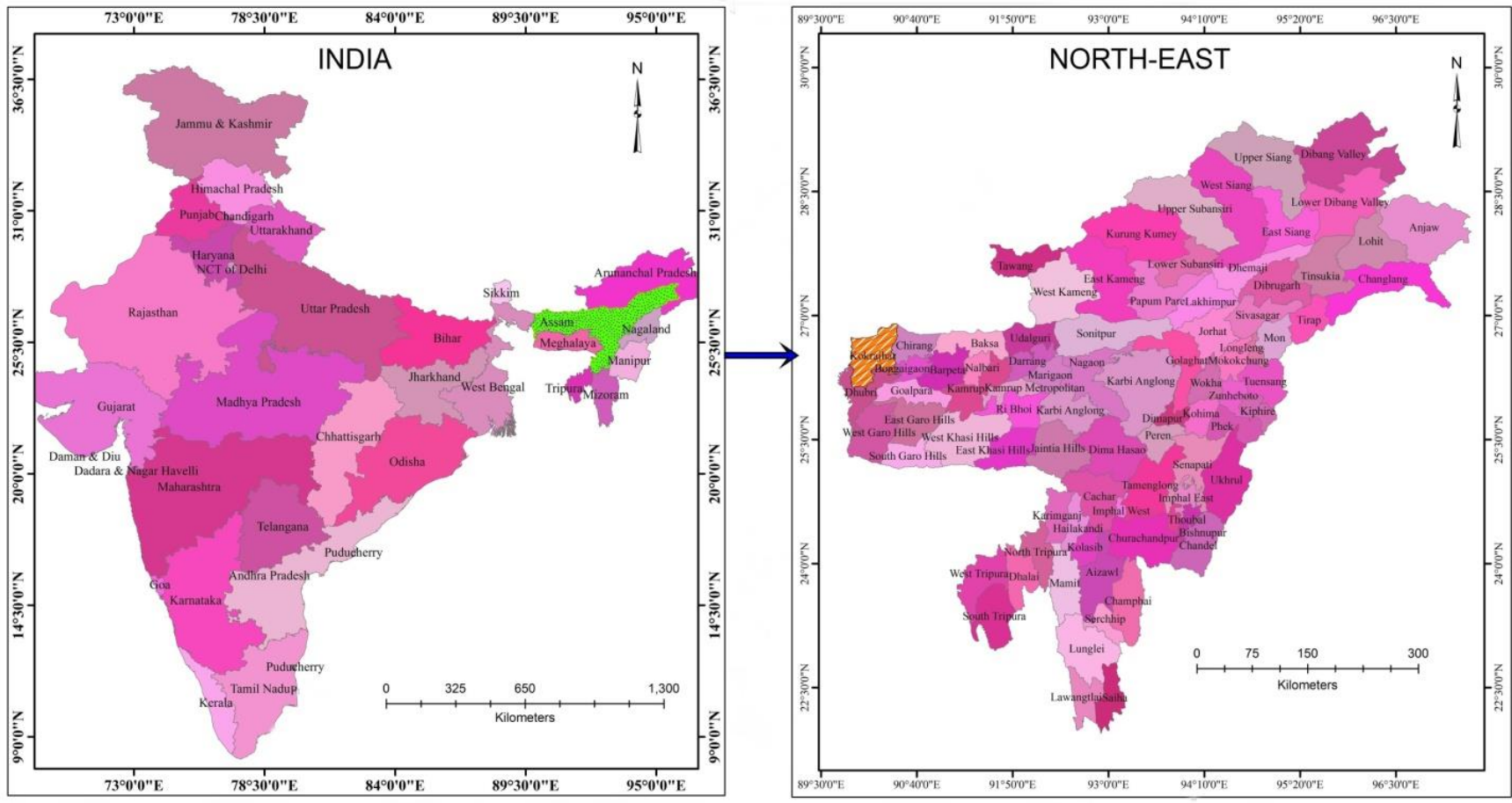

\section{E. Methodology of the Study}

In this paper, descriptive and analytic method has been used. Data is mainly collected from the secondary sources of published and unpublished sources including journals, articles and Internet and government websites. The collected data is based on health infrastructure available in Kokrajhar district. The sample data is also taken from the state of Assam and India to compare the availability of heath infrastructure. The collected information has been formulated with the help of some statistical method to find out the results and the same has been shown with tables. The location map of the study area is prepared on QGIS by digitizing it on the Google Earth.

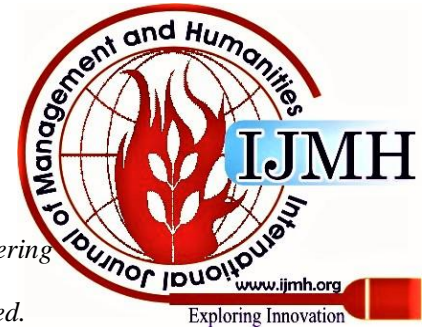




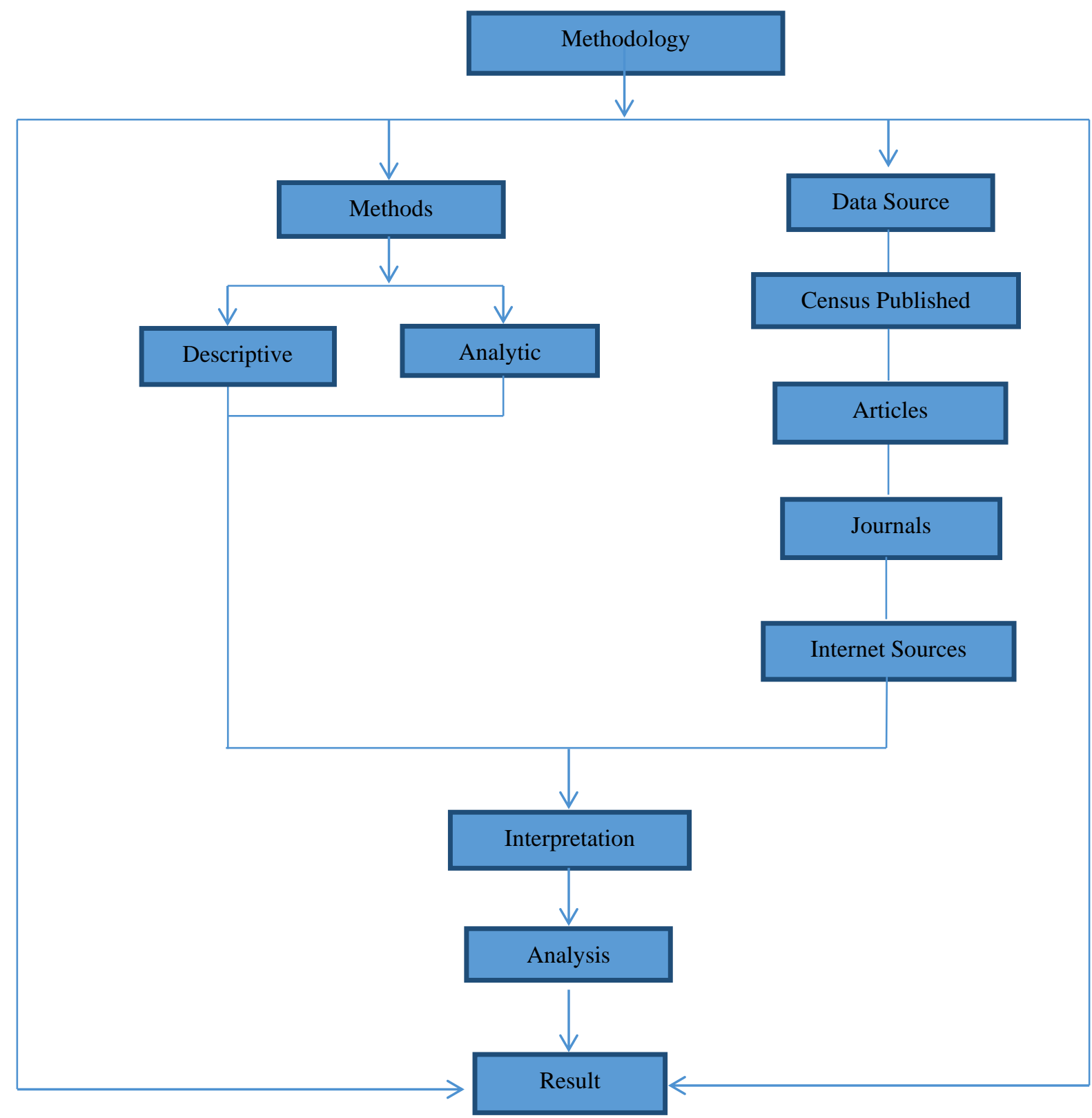

\section{INTERPRETATION AND ANALYSIS}

\section{A. Healthcare Facilities}

Health care is the prevention, treatment and management of illness and the preservation of health through the services offered by health care organizations and professionals. It includes all the goods and services designed to promote health, including preventive, curative and palliative interventions, whether directed to individuals or to populations. Health infrastructure is an important indicator for understanding the health care policy and welfare mechanism in a country. It signifies the investment priority with regards to the creation of health care facilities. India has one of the largest populations in the world; coupled with this wide spread poverty becomes a serious problem in India (Kumar and Gupta, 2012). The health care services ought to possess four basic characteristics such as availability, accessibility, affordability and quality with regard to both

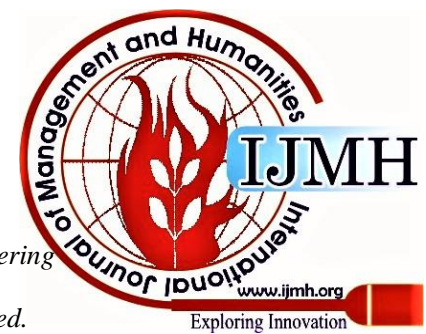


Table 1: Healthcare Facilities in Kokrajhar, Assam and India as per 2011 Census.

\begin{tabular}{|c|c|c|c|c|c|c|c|c|c|c|}
\hline \multirow{2}{*}{ Region } & \multicolumn{2}{|c|}{ SCs } & \multicolumn{2}{c|}{ PHCs } & \multicolumn{2}{c|}{ CHCs } & \multicolumn{2}{c|}{ SDHs } & \multicolumn{2}{c|}{ DHs } \\
\cline { 2 - 10 } & $\begin{array}{c}\text { No. of } \\
\text { SCs }\end{array}$ & $\begin{array}{c}\text { Total } \\
\text { Population }\end{array}$ & $\begin{array}{c}\text { No. of } \\
\text { PHCs }\end{array}$ & $\begin{array}{c}\text { Total } \\
\text { population }\end{array}$ & $\begin{array}{c}\text { No. of } \\
\text { CHCs }\end{array}$ & $\begin{array}{c}\text { Total } \\
\text { Population }\end{array}$ & $\begin{array}{c}\text { No. of } \\
\text { SDHs }\end{array}$ & $\begin{array}{c}\text { Total } \\
\text { Population }\end{array}$ & $\begin{array}{c}\text { No. of } \\
\text { DHs }\end{array}$ & $\begin{array}{c}\text { Total } \\
\text { Population }\end{array}$ \\
\hline Kokrajhar & 161 & 887142 & 45 & 887142 & 4 & 887142 & 1 & 887142 & 1 & 887142 \\
\hline Assam & 4621 & 31169272 & 1014 & 31169272 & 151 & 31169272 & 13 & 31169272 & 25 & 31169272 \\
\hline India & 153655 & 1210193422 & 25308 & 1210193422 & 5396 & 1210193422 & 1022 & 1210193422 & 763 & 1210193422 \\
\hline
\end{tabular}

Source: Rural Health Statistics, 2014-15.

In the state of Assam, the healthcare system is organized into primary, secondary, and tertiary levels. At the primary level are the Sub Centers (SCs) and Primary Health Centers (PHCs). At the secondary level, there are Community Health Centers (CHC) and smaller Sub-divisional hospitals and in the tertiary level, District or General Hospitals are found.

\section{B. Sub Centres (SCs)}

A Sub Centre (SC) is designed to serve extremely rural areas with the expenses fully covered by the national government. As per the guidelines of rural health statistics, the requirement of health staff should be at least two workers (male and female) to serve a population of 5000 people which is 3000 in case of remote areas. Sub Centers are assigned with tasks related to interpersonal communication in order to bring about behavioral change and provide services in relation to maternal and child health, family welfare, nutrition, immunization, diarrhea control and control of communicable diseases programmes. Each Sub Centre is required to be manned by at least one Auxiliary Nurse Midwife (ANM) / female health worker and one male health worker. Sub Centres also work to educate rural people about healthy habits for long-term impact. In Kokrajhar district, there are about 161 Sub Centers (Table 1) with an average population of 5510 each which is much higher than the mentioned guidelines. In the state level, there are about 4621 sub centers with an average population of 6745 persons (Table 1) and at the national level, there are about 1,53,655 SCs with an average population of 7876 person each. From that point of view, the national average is higher than the state of Assam and Kokrajhar district. Although the ratio is less compared to the state and the nation, the facility in the district is very poor. The building structure of the SCs in the district is in very pathetic conditions. About $90 \%$ of the SCs in the district have no facilities of drinking water, sanitation facility etc. The medical treatment like maternal checkup, general medical checkup etc. has not been done on regular basis because of lack of proper management system and lack of infrastructure.

\section{Primary Health Centre}

Primary care refers to first-contact, continuous, comprehensive, and coordinated care provided to individuals regardless of gender, disease, or organ system affected (Hu, et al, 2016). Primary Health Centres (PHCs) exist in more developed rural areas of 30,000 or more population (20,000 in remote areas) and serve with larger health clinics staffed with doctors and paramedics. The PHCs are envisaged to provide an integrated curative and preventive health care to the rural population with emphasis on preventive and promotive aspects of health care. As per the guidelines of rural health statistics, PHC is to be manned by a medical officer supported by 14 paramedical and other staffs. It acts as a referral unit for 6 Sub Centers and has $4-6$ beds for patients. The activities of PHC involve curative, preventive, promotive and family welfare services. Patients can be referred from local SCs to PHCs for diseases which are more complex in nature. PHCs also function to improve health education with a larger emphasis on preventative measures. There are about 45 public PHCs (Table 1) in the district and about 1014 in the state and 25,308 PHCs throughout the country. The average population ratio of district is about 19,714 each and it is less than the state average of 30738 and national level average of 47818 people. Many PHCs in the district are manned with insufficient workforce and they are running with a minimal number of ANMs, Doctors and other nursing staffs. There is also lack of physical infrastructure. The required medical equipment for seasonal fever is also not available as there is poor maintenance. Because of all this, people in the district prefer to go to the private health centres instead of going to public health centres for their health check up.

\section{Community Health Centre and Sub Divisional Hospital}

The Community Health Centre (CHC) is a model to provide better or equal quality primary care when compared with other health care facilities, which would encourage patients to seek primary care in CHCs (Hu et al, 2016). It serves 120,000 people in urban areas and 80,000 people in remote areas. Patients from these agencies can be transferred to general hospitals for further treatments. The CHC is required to be manned by four medical specialists i.e. Surgeon, Physician, Gynecologist and Pediatrician supported by 21 paramedical and other staffs. It has 30 in-door beds with one OT, X-ray and labor room and laboratory facilities. It serves as a referral center for 4 PHCs and also provides facilities for obstetric care and specialist consultations. Thus, the CHCs are also First Referral Units (FRU) which are required to have obstetric care, new born/childcare and blood storage capacities at all hours every day of the week. There are about 4 CHCs (Table 1) in the district located at Gossaigaon, Kochugaon, Balajan and Dotma and at present they are providing services to about 2,21,785 persons on an average. 
The SDH is located in Gossaigaon Sub division of Kokrajhar district known as RNB civil Hospital. In the state of Assam, there are about 151 CHCs and 13 SDHs serving with an average population of 206419 each. In the national level, the total number of CHCs is about 5396 and SDHs of 1022 serving with an average population of 224276 people each. Some CHCs and SDHs in the district are running without sufficient workforce with limited medical equipments. As per source, about $30 \%$ of the district CHCs and SDHs do not have specialists and other workforce and there is also a lack of required building infrastructure. This is one of the reasons why people prefer to visit the private health care centres in the district instead of availing the treatments in the CHCs and SDHs.

\section{E. District Hospitals}

District Hospitals (DH) are the final referral center for the primary and secondary levels of the public health system. It is expected that there should be at least one hospital is in each district of India. There are about 763 DHs (Table 1) throughout the country found to be located in 736 districts of India. There are on an average 75 to 500 beds found in the DHs depending on population of districts. These district hospitals often lack modern equipments and relations with local blood banks. There is a district hospital located at Kokrajhar main town serving the population of the district. The district hospital is named RNB civil Hospital, Kokrajhar.
At present, there are about 25 DHs in the state of Assam serving with an average population of 12 , 46,770 people each. The state average is more than that the district average and the facilities provided are also not up to the mark. That is why people from the state prefer to go outside the state for quality treatment. It is observed that every year thousands of people move to other cities of the country like Chennai, Bangalore, Mumbai etc. for better and quality medical treatment.

\section{F. Human resources}

Good health care facilities depend on the efficient and skilled health workers. The health condition of the people of a nation largely depends on an effective and well developed health- care system. However, even after six decades of planned development programmes initiated in India, its health-care sector is quite unsatisfactory (Saikia and Das, 2014). With minimal number of doctors, ANMs, nursing staffs, other workers, a health center cannot be effectively maintained. The total workforce in India is 12, 24,181 in the public health sector (Table 2). Among these 27,421 are doctors, 2, 12,185 are ANMs, 8, 70,089 are ASHAs and other health staffs.

Table 2: Health Workers of Kokrajhar, Assam and India, 2015

\begin{tabular}{|c|c|c|c|}
\hline Manpower & Kokrajhar & Assam & India \\
\hline Doctors at PHCs & 838 & 1355 & 27421 \\
\hline ANMs in SCs & 320 & 9220 & 4078 \\
\hline Specialist in CHCs & N/A & 121 & 2150 \\
\hline Radiologist in CHCs & N/A & 65 & 23131 \\
\hline Pharmacist at PHCs/CHCs & N/A & 1347 & 17154 \\
\hline Lab technician at PHCs/CHCs & N/A & 1225 & 65039 \\
\hline Nursing staff at PHCs/CHCs & N/A & 3056 & 870089 \\
\hline ASHAs & 1335 & 29693 & 2934 \\
\hline
\end{tabular}

Source: Rural Health Statistics, 2014-15.

The number of health workers in Kokrajhar district are like Doctors (838), ANMs (320) and ASHAs (1335). The average ratio of Doctors and total population of the district is higher than the national and state ratio. As per Rural Health Statistical guidelines, the number of doctors in the district is lesser than what it is supposed to be. There are a number of PHCs and CHCs in the district, in which the number of health workforce are inadequate. There are many vacant posts in the health sector which are yet to be filled up in the district. Doctors do not want to serve in rural areas for which the posts remain vacant. Many of the health centres in the district are run with limited or without permanent doctors.

\section{G. Shortfall of Healthcare Facilities}

The shortfall of drugs and medical equipment is also one of the major concerns in the district as well as for the state of Assam. India has a mixed health-care system, which include public and private health-care service providers. However, most of the private health-care providers are concentrated in urban India, providing secondary and tertiary health-care services (Chokshi et.al, 2016). There is a shortfall of physical infrastructure mostly in rural India and the district Kokrajhar is no exception to this.. The lack of infrastructure is the major concern for the low status of health sector in the country. In India, there is a total shortfall of 2, 17,179 physical infrastructure (Table 3) which include SCs, PHCs, CHCs, SDHs and DHs. Among these, the total requirement of SCs in the country is about 1, 79,240 whereas, the shortfall in PHCs is 29337, in CHCs is 7322, in SDHs 640 and in DHs is 640. In the state level, the total shortfall of SCs is 5850. In the state level, the total requirement of the health infrastructure is about 7108. Out of these 5850 are SCs, 954 are PHCs, 238 are CHCs and 33 each for both the SDHs and DHs.

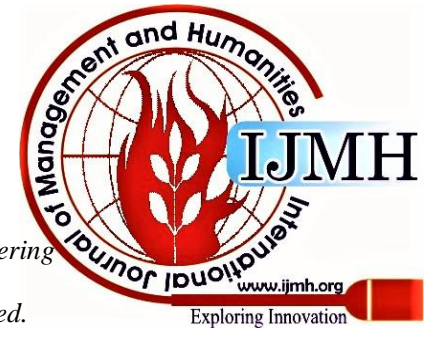


The total requirement of physical infrastructure in Kokrajhar district is 219. Out of these 166 are SCs, 41 are PHCs, 10 are CHCs, 1 SDH and 1 DH. Hence, India should focus on increasing the number of primary health infrastructure to strengthen the health sector in the country.

Table 3: Shortfall of Healthcare Facilities in Kokrajhar, Assam and India as per 2011

\begin{tabular}{|c|c|c|c|c|c|c|c|c|c|c|}
\hline \multirow{2}{*}{ Region } & \multicolumn{2}{|c|}{ SCs } & \multicolumn{2}{c|}{ PHCs } & \multicolumn{2}{c|}{ CHCs } & \multicolumn{2}{c|}{ SDHs } & \multicolumn{2}{c|}{ DHs } \\
\cline { 2 - 12 } & Require & $\begin{array}{c}\text { In } \\
\text { Position }\end{array}$ & Require & $\begin{array}{c}\text { In } \\
\text { Position }\end{array}$ & Require & $\begin{array}{c}\text { In } \\
\text { Position }\end{array}$ & Require & $\begin{array}{c}\text { In } \\
\text { Position }\end{array}$ & Require & $\begin{array}{c}\text { In } \\
\text { Position }\end{array}$ \\
\hline Kokrajhar & 166 & 161 & 41 & 45 & 10 & 5 & 1 & 1 & 1 & 1 \\
\hline Assam & 5850 & 4621 & 954 & 1014 & 238 & 151 & 33 & 13 & 33 & 25 \\
\hline India & 179240 & 153655 & 29337 & 25308 & 7322 & 5396 & 640 & 1022 & 640 & 1253 \\
\hline
\end{tabular}

Source: Rural Health Statistics, 2014-15

There is also a shortfall of workforce in the health sector in our country. These shortfalls of both physical infrastructure and workforce have become a serious issue either in primary or secondary health care level in the country. Lack of skilled service provider is one of the biggest constraints in India. The country currently needs an additional of 6.4 million healthcare workers to serve its population. Due to lack of both physical infrastructure and manpower, India has not been able to strengthen the health care system as expected and the status of health facilities are very low as compared to other nations in the world. The total number of shortfall of manpower in the public health sector is about $12,25,828$ (Table 4). Apart from these, more workers are needed at various levels to serve the country's total population.

Table 4: Shortfall of Health Worker of Kokrajhar, Assam and India, 2015.

\begin{tabular}{|c|c|c|c|c|c|c|c|c|c|c|c|c|c|c|c|c|}
\hline \multirow[t]{2}{*}{ Region } & \multicolumn{2}{|c|}{$\begin{array}{l}\text { Doctors at } \\
\text { PHCs }\end{array}$} & \multicolumn{2}{|c|}{$\begin{array}{c}\text { Specialist at } \\
\text { CHCs }\end{array}$} & \multicolumn{2}{|c|}{$\begin{array}{c}\text { ANMs at SCs\& } \\
\text { PHCs }\end{array}$} & \multicolumn{2}{|c|}{$\begin{array}{c}\text { Radiographers } \\
\text { at CHCs }\end{array}$} & \multicolumn{2}{|c|}{$\begin{array}{l}\text { Lab } \\
\text { Technicians } \\
\text { at PHCs\& } \\
\text { CHCs }\end{array}$} & \multicolumn{2}{|c|}{$\begin{array}{c}\text { Nursing } \\
\text { Staffs at } \\
\text { PHCs \& } \\
\text { CHCs }\end{array}$} & \multicolumn{2}{|c|}{ ASHAs } & \multicolumn{2}{|c|}{$\begin{array}{c}\text { Pharmacists } \\
\text { at PHCs \& } \\
\text { CHCs }\end{array}$} \\
\hline & 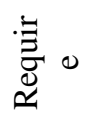 & $\sum_{3}^{0}$ & 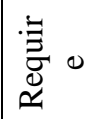 & 丞 & $\underset{\mathscr{Z}}{\mathscr{\Xi}}$ & $\sum^{3}$ & 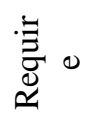 & 赵 & $\underset{\mathscr{Z}}{\mathscr{\Xi}}$ & $\sum_{3}^{\circ}$ & $\stackrel{\Xi}{\stackrel{\Xi}{\Xi}}$ & $\sum^{i}$ & $\underset{\mathscr{\Xi}}{\stackrel{\Xi}{\Xi}}$ & $\sum_{3}^{3}$ & 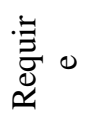 & $\sum_{3}^{\circ}$ \\
\hline Kokrajhar & N/A & 35 & 20 & 13 & 431 & 320 & 5 & N/A & 50 & N/A & 315 & N/A & 1072 & 1335 & 50 & N/A \\
\hline Assam & 1014 & 1355 & 604 & 121 & 5635 & 9220 & 151 & 65 & 1165 & 1225 & 2071 & 3056 & 30507 & 29693 & 1165 & 1347 \\
\hline India & 25308 & 27421 & 21584 & 4078 & 178963 & 212185 & 5396 & 2150 & 30704 & 17154 & 63080 & 65039 & 870089 & 859331 & 30704 & 23131 \\
\hline
\end{tabular}

Source: Rural Health Statistics, 2014-15.

The total shortfall of workforce in the state is about 42,312 including ASHAs, ANMs, Doctors, nursing staffs and others. Out of these, the largest number of shortfall of health worker is the ASHA workers which need to be added with 30,507 ASHA workers to meet the requirement. In Kokrajhar district also, there is shortfall of health workers. There is shortage of Doctors, ANMs, Nursing staffs, and other health workers in public health sectors at various levels. The total requirement of ASHA workers in the district is about 1072. Many health centers in the district are run with the minimal number of doctors, ANMs, Nursing staffs, and other health workers. The infrastructure of SCs, PHCs and CHCs are also in a pitiable condition, which cannot be compared with the infrastructure facilities available in other districts

\section{CAUSES OF POOR HEALTH STATUS}

\section{A. Accessibility}

Accessibility is one of the major constraints in the district. Since the health facility is limited in the district, people regularly move to other districts in the state or to the neighbouring state of West Bengal for better medical treatment. The health-care facilities have to be accessible within safe physical reach to everyone at affordable cost without discrimination. Most of the people have to travel in private hired vehicles to reach the healthcare centers for their treatment, which is very expensive for the poor people. However, the accessibility of health-care services within safe physical reach across the northeastern states is not quite satisfactory (Saikia and Das, 2014). The geographical isolation might be the mentionable factor for the cause of inaccessibility of Kokrajhar district. Kokrajhar district is situated far away from the state head quarters for which the administration has failed to provide equal opportunity like other districts of the state.

This has created dissatisfaction in the minds of the people. However, the road connectivity is also in a very pathetic condition in the district. Most importantly there is also lack of proper drinking water facilities, Sanitation, shelter and other basic requirements for the livelihood. Sanitation and safe drinking water play a vital role in maintaining good health of the people.

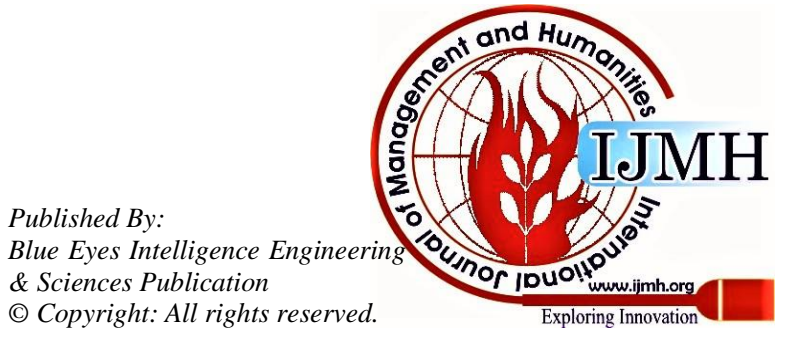


There may be various reasons of having poor sanitary conditions in the region which may be due to poor socio-economic conditions, cultural behavior, educational attainment and traditional livelihood system. Most of the time, patients with chronic diseases such as Tuberculosis, Cancer etc. have to remain without treatment. Moreover, their poor economic conditions also do not permit them to go for medical treatment in other cities. But due to the efforts of the National Rural Health Mission, awareness has come among the females and now women folks are seen visiting the neighbouring hospitals regularly for pregnancy checkup (Basumatary, 2019). Although, the health department of the state government today has provided ambulance services in emergency case, yet the majority villagers of the district are not aware about it and have not been able to avail the facility. That is why most of the births used to be at home.

\section{B. Poverty}

The people in the study area are poor as majority of them are tribals and other downtrodden people. Like other tribals, majority of the people in the district have no idea about the value of money. (Basumatary, 2019). Whatever is earned by working in the field either as labourers or from selling agricultural products, vegetables, fish etc. they spend all without saving. Hence, majority of the people are living in abject poverty. Poverty is often directly linked with the poor health condition of the people. Three fourth of the population live below or at subsistence levels (Gangolli et al, 2005). Health is closely related with the accretion and persistence of poverty. Ill-health leads to capability deprivation and hence poverty, which again stands for a low standard of living implying low intake of food, malnutrition, lack of basic amenities such as poor housing, clothing, safe drinking water and sanitation facilities (Buragohain, 2015). In addition to economic constraints, there are also cultural constraints that affect people's ability or likelihood to enter a medical setting. Those who fall into poverty and remain poor are also suffering from many diseases, in that situation if health facility is not available for them than they will be unable to overcome the poverty (Paul et al, 2019). While gender disparities continue to be prevalent in the health sector, the extent to which it occurs within poor communities often depends on factors like the socioeconomic conditions, cultural differences and even age. Children living in poverty have limited access to basic health facilities. Gender inequalities in health for those living in poverty continue into adulthood. In research that excluded women's health disadvantages (childbirth, pregnancy, susceptibility to HIV, etc.) it was found that there was not a significant gender difference in diagnosis and treatment of chronic conditions. In fact, women were diagnosed more, which was attributed to the fact that women had more access to healthcare due to reproductive needs, or from taking their children in for checkups. By contrast, research that was inclusive of women's health disadvantages revealed that maternal health widened. However more than $90 \%$ people of district are living in rural areas and their major economic sources is from agriculture and other primary activities. Their longevity of life is lesser than the national level and as majority of the people die before the average age of death in the country due to their poor economic condition and the various diseases they suffer from.

\section{Cultural Norms and Practices}

Cultural norms and practices are two of the main reasons why gender disparities in health exist and continue to persist. These cultural norms and practices often influence the roles and behavior that men and women in the society. It is these gender differences between men and women, which are regarded and valued differently, that give rise to gender inequalities as they work to systematically empower one group and oppress the other. Both gender differences and gender inequalities can lead to disparities in health outcomes and access to health care. Some of the examples provided by the World Health Organization (WHO) of how cultural norms can result in gender disparities in health include a woman's inability to travel alone, which can prevent them from receiving the necessary health care that they need. Another societal standard is a woman's inability to insist on condom use by her spouse or sex partners, leading to a higher risk of contracting communicable diseases. As they lack of sanitation, maximum family do not have proper sanitation facilities and they have been practicing open defecation. This traditional system could be a reason for occurrence of communicable diseases. Additionally, child marriage is also another reason for low status of health, where a boy or girl before becoming matured and without proper education, get married. This has also become a common practice among the children in the study area and the health of the married girls is in stake. This is the reason why the maternal death rate is higher in the district. And it has strong relationship with the health status of a particular region.

\section{Health Expenditure in Assam and India}

The efficiency of public health care services depend on the usefulness of health care expenses. The expenses on medical and public health have direct impact on the health condition of the community, but expenses on sanitation, water supply and nutrition have a larger indirect positive impact on the health condition of the poor people in rural areas. The total health expenses divided into two parts: Public Expenditure and Private Expenditure. The Public Expenditure clearly indicates that Assam is the only state where 79 percent of total expenditure is private and only 21 percent is public expenditure. India's health expenditure is mostly dominated by private sectors but the situation is different in North-East India. About 80 percent of total health expenditure in India is private and only 20 percent in the public sector. The North-East India has relatively better situation in terms of public expenditure. The share of public expenditure is 31 percent out of total health expenditure and remaining 69 percent for private expenditure. th and $H$ 
Table 5: Central and State expenditure on Health Sector

\begin{tabular}{|c|c|c|c|}
\hline Region & $\begin{array}{c}\text { Allocation } \\
\text { (in Rs Crore) }\end{array}$ & $\begin{array}{c}\text { Budgeted } \\
\text { (in Rs Crore) }\end{array}$ & $\begin{array}{c}\text { Actual } \\
\text { Budget } \\
\text { (in Rs Crore) }\end{array}$ \\
\hline Assam & 2717 & 7050 & 4642 \\
\hline India & 64609 & 64559 & 54682 \\
\hline
\end{tabular}

Source: Assam Budget Documents 2020-21, Expenditure Budget, Union Budget 2020-21; PRS

During the annual budget of 20201-21 session, the expenditure on health sector allocated amount was Rs. 64609 Crore only but the budgeted amount was Rs. 64559 Crore which is higher than the amount of actual budget (Table 5). In contrast to this, the state has total expenditure on health sector was Rs. 2717 Crore. The actual budget of the state was Rs. 4642 Crore and there is a huge difference between the allotted budget and actual budget. There could be some reasons as actual budget of state has not been utilized.

\section{SUGGESTIONS AND CONCLUSIONS}

\section{A. Suggestions}

The following suggestion may be put forward for the development of health care facilities in the region.

1. Primary care should play a central role in the face of increasing pressure from demographic, epidemiological and socio-economic forces.

2. Health facilities should be developed in the rural sector by public authorities and incentives for the same should be provided to private bodies.

3. More effective policies should be adopted by the state government to attract the doctors towards the rural areas for the development of health sector in the villages.

4. Health awareness programmes should be conducted regularly especially in the rural areas to bring awareness among the masses about the health issues.

5 . The medical equipment should be made available be it in the rural areas or urban areas to help the people to get their diseases diagnosed in their own locality without having to move to other cities for the same.

6 . The central and state government should focus on the improvement of the basic necessities including drinking water, improved sanitation facilities, using clean fuel for cooking etc. and there should be inspection of the healthcare centers regularly by the authority.

7. The number of medical colleges and other training centres pertaining to health department should be increased to provide scope to the people to undergo medical training and education in the district as well as in the state.

8. The central and state government should increase the physical infrastructure and manpower as per the population and the posts lying vacant should be filled up without further delay.

9. The allotted fund meant for the improvement of infrastructure and others should be utilized as per the guidelines and proper measures should be taken at various levels for the implementation of the schemes related to health sector.

\section{B. Cultural Norms and Practices}

Health is a matter of the state and hence it is the duty of the state government to adopt appropriate measures to provide best health care facilities to everyone residing in Assam. Health status among the district population of Assam is not at all satisfactory. Shifting of health care from the public to private sector compel the people to borne heavy financial burden and since in many cases treatment option is only with the private sector and therefore, poor people can't afford those high cost treatments and many people have to die without proper medical treatment. Efforts must be made to provide the people with safe drinking water, toilet facilities, housing and electricity. Self-employment and employment opportunities; quality education facilities; access to banking and all weather roads are also essential requirement for improving the health status of the people of Assam. The rural health care infrastructure as well as the health status of the people of the rural areas of Assam is not satisfactory and without a concerted effort from the government both central and particularly the state. And many health care centres in the district are running with minimal facilities. Although India has made considerable progress in health infrastructure under NRHM, the improvement has been quite uneven across regions with large-scale inter-state variations. The rural health-care sector in the country as well as the state suffers from shortages of well-trained health workers. Even though the posts of various cadres of health workers are sanctioned, many of them are lying vacant in almost all the states, resulting in under-utilization of facilities available in the existing health centers and subsequently, closure of those facilities. The government should make all out efforts to fill the vacant posts in health sector to provide better health care facilities to the rural masses and bring the doctor population ratio at par with the recommendations of the WHO.

\section{REFERENCES}

1. Buragohain, P. P. (2015), STATUS OF RURAL HEALTH INFRASTUCTURE OF ASSAM, Research Paper Impact Factor: 3.029 Peer Reviewed \& Indexed Journal, IJMSRR E- ISSN 2349-6746 ISSN -2349-6738.

2. Basumatary, M. (2019), Socio-Economic conditions of the Adivashis in the Santal Colony of Assam, Associated Asia Research Foundation, India, p.28

3. Choudhury, S. (2018), Health Scenario of Assam: A Study. International Journal of Advance Research, Ideas and Innovations in Technology.

4. Devi, Nirmala (2016), Status of Health among Rural Households of Assam: A Study in Reference to Public Health Sector, Department of Humanities and Social Science, Indian Institute of Technology, Guwahati.

5. Gangolli, L. V., et al, (2005), Review of Healthcare In India, Centre for Enquiry into Health and Allied Themes, Research Centre of Anusandhan Trust, Survey No. 2804 \& 2805, Aaram Society Road, Vakola, Santa Cruz East, Mumbai - 400055, Maharashtra, India.

6. Hajra, G. (2017), IMPACT OF SANITATION ON WATERBORNE DISEASES: THE CASE OF INDIA, Department of Economics University of Calcutta 2017.

7. Hu Ruwei et al. (2016), Types of health care facilities and the quality of primary care: a study of characteristics and experiences of Chinese patients in Guangdong Province, China, BMC Health Services Research (2016)

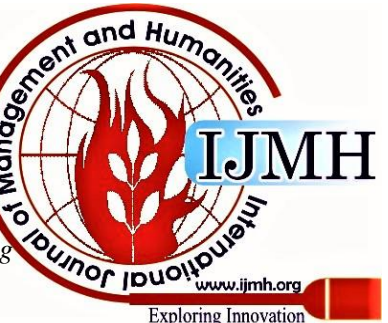


8. HemkhothangLhungdim and PerianayagamArokiasamy, Health System Performance Assessment, World Health Survey-2003, Assam Report, 2006, International Institute for Population Science (IIPS), WHO.

9. Kumar, A. and Gupta, S. (2012), Health infrastructure in India: Critical Analysis of Policy gaps in the Indian healthcare delivery, Vivekananda International Foundation, Occasional paper, July 2012.

10. M Chokshi, B Patil, R Khanna, S B Neogi, J Sharma, V K Paul, and S Zodpey, Health systems in India, Journal of Perinatology, J Perinatol. 2016 Dec; 36(Suppl 3): S9-S12.

11. Paul P.K., et al (2019) An Analysis of Health Status of the State of Assam, India, RESEARCH REVIEW International Journal of Multidisciplinary, Volume-04 Issue-03 March-2019.

12. SAIKIA, D, et al. (2014) Access to Public Health-Care in the Rural Northeast India, The NEHU Journal, Vol XII, No. 2, July - December 2014, pp. 77-100 ISSN. 0972 - 8406

13. S. Bonu, M. Rani, (2008), Health Systems of South Asia, International Encyclopedia of Public Health.

14. Assam Preliminary Factsheet (2016), Comprehensive National Nutrition Survey, 2016.

15. Economic survey 2019-20.

16. Government of India (2018), National Health Profile 2018, 13th Issue, Central Bureau of Health Intelligence.

17. Rural Health Statistics, 2014-15, Government of India, ministry of Health and Family Welfare, Statistics Division.

18. https://www.prsindia.org/parliamenttrack/budgets/union-budget-2020 -21-analysis

19. https://www.prsindia.org/parliamenttrack/budgets/assam-budget-anal ysis-2020-21.

20. http://timesofindia.com

21. http://Sentinelassam.com, Shortage of Doctors in Assam and its effects on patients-2019

22. Mattersindia.com/2017/10/, Assam is facing severe shortage of doctors by R.Dutta Choudhury, October, 2017

\section{AUTHORS PROFILE}

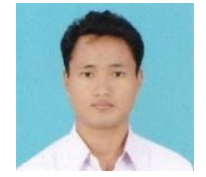

Gwmsath Mushahary, has completed his graduation with honours in Geography from Gossaigaon College, Gossaigaon and masters degree from Department of Geography, Bodoland Universit with specialization in Geomorphology in .He was born in February, 04, 1994 in a remote village of Mojatigaon, Kokrajhar, Assam. Mr. Mushahary is currently teaching Geograpahy at Gossaigaon College as Guest lecturer.

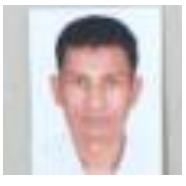

Dr. Manjil Basumatary, has completed his masters degree in Geography from Nort Eastren Hill University (NEHU), Shillong in the year 1995 and $\mathrm{Ph}$. D. from Gauhati University in 2010. Dr. Basumatary is currently teaching Geography in Under graduate (UG) and Post Graduate(PG) level at Gossaigaon College, Gossaigaon, Kokrajahr, Assam. He is a seasoned writer and publishes articles pertaining to the issues related to the western part of Assam. His area of interest is Peace and Conflict studies and has published papers related to conflict in the region in various journals and magazines. Dr. Basumatary has also presented number of papers at the national and international conferences held in the country and abroad related to conflict and other issues of the region. Besides teaching, Dr. Basumatary has also undergone National Cadet Corps (NCC) training for a eriod of three months at the Officers Training Academy (OTA), Kamptee, Nagpur in 2008 and commissioned as Lieuftenant and thereafter promoted to the rank of Captain in the NCC in 2014. 